\section{Fads and friction}

Jacqueline Reynolds

The Culture of Science in France, 1700-1900. By Robert Fox. Variorum*: 1992. No pagination. $£ 47.50, \$ 89.95$.

SOCIETY in France during the eighteenth and nineteenth centuries was characterized by enormous upheavals, leaps forward and painful retreats. History records the end of the reign of the 'Sun King' Louis XIV, the ineffectual rule of his successor, the brutal singularity of the Revolution, the rise of Napoleon, the restoration of the monarchy, the formation of the Third Republic. And all the while, French scientists continued to do just what they had always done make new discoveries and expand our understanding of the natural world. This was the period of great excitement at the Jardin du Roi with Buffon, Cuvier and Lamarck, and of that famous duo in Arcueil, Berthollet and Laplace. Lavoisier set the foundation for modern chemistry; Ampère published his monumental treatise on electricity and magnetism; Carnot established the second law of thermodynamics; Fresnel demonstrated the wave nature of light. What a record of achievement!

Robert Fox in his fascination with "the diversity of the contexts in which the French pursued science" has put together 12 of his own papers (all published elsewhere between 1968 and 1985) that describe the changing nature of government influence, scientific institutions and the approach to scientific discovery between 1700 and 1900 . There is inevitably a problem with continuity as well as some mildly annoying repetition, but such is the nature of collected studies written so far apart in time.

The first half of the book centres on society and institutions. Fox addresses the attitudes of successive governments towards scientific endeavour, ranging from active encouragement during the Napoleonic days to indifference in the post-Restoration era. We are shown how scientists themselves evolved through these periods both in their approach to research and in their personal attitudes towards fame and fortune. These individual differences, rather than government interventions (or the lack thereof), were in the author's view the real causes of the changing face of French science. The rise of numerous sociétés savants is one of the most interesting aspects of this period, with their accommodation of not just professional scientists but anyone who could be induced to participate and part with the fee charged for annual

* Ashgate Publishing Group, Croft Road, Aldershot, Hamp shire GU11 3HR, UK.

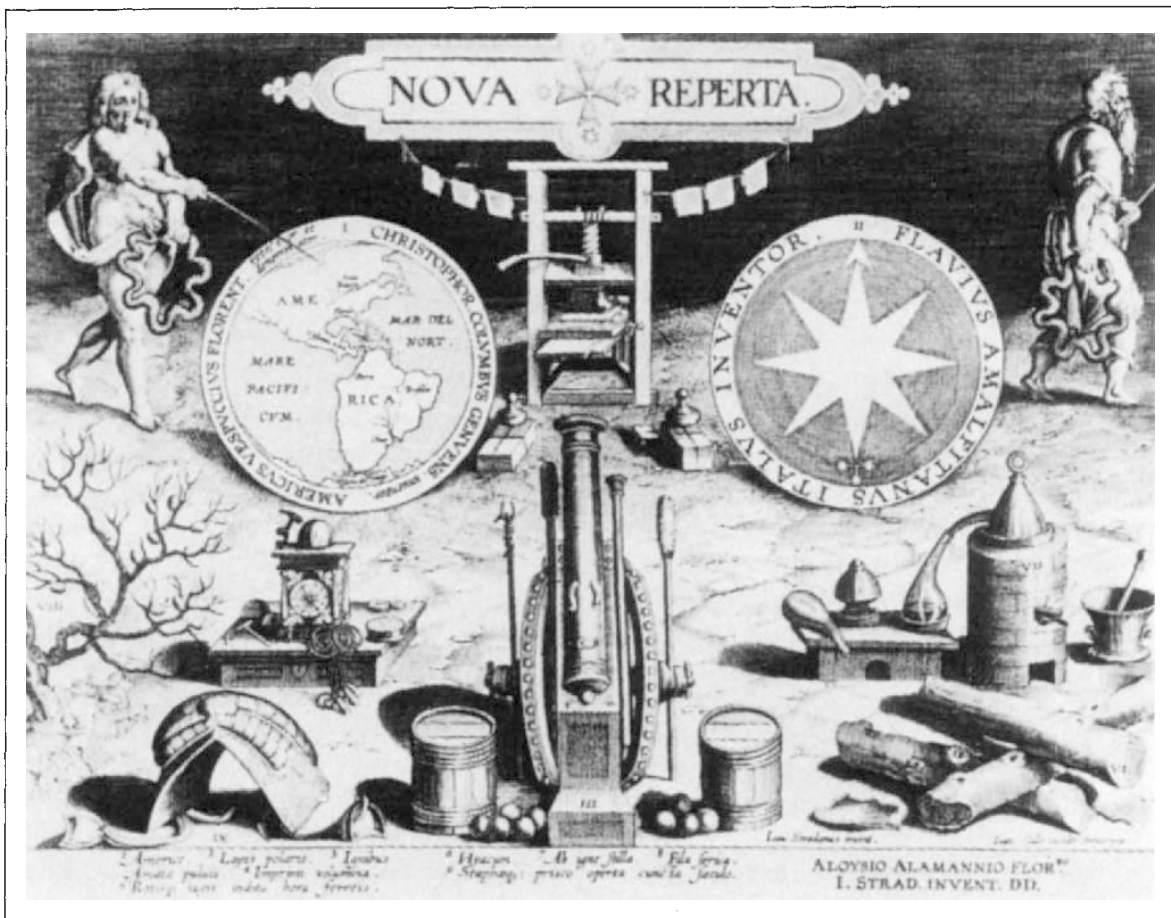

ANCIENTS and moderns - an engraving by Johannes Galle of the title page of the Flemish artist Johannes Stradanus's serles of nova reperta, or new dlscoverles, drawn in the 1550s. The drawings Illustrate silk manufacture and sericulture, the discovery of the New World, lodestone, gunpowder, printing, clocks, dlstilled alcohol, stirrups, milis and spectacles. This picture appears in The Mastery of Nature by T. DaCosta Kaufmann, a collectlon of essays on art, sclence and

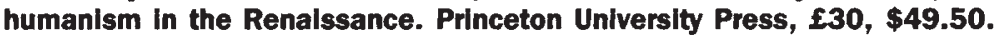

membership. Inevitably, these sociétés became ever more specialized and less accessible intellectually to the layman, so that by the end of the nineteenth century the universal savant had effectively disappeared. Most of Fox's societal framework refers to the provinces and not the better known institutions centralized in Paris, an approach that makes a refreshing change. In fact, one of the most fascinating chapters deals with the history of Mulhouse and the meeting between science and industry in this region of shifting political allegiance far from the centralist powers in Paris.

But all is not politics and institutions. As Goethe said, "The history of science is science itself" and, appropriately, Fox uses the history of the study of heat in eighteenth and nineteenth century France to demonstrate the changing aspirations and preoccupations of the participating scientists. There is Lambert's 'particles of fire' theory of heat set in the context of the arguments that raged at the time: that is, heat as a fluid (caloric) versus heat as motion (kinetic). Dulong and Petit appear with their study of specific heats, the results of which dealt a severe blow to the Laplacian school that supported the caloric theory. The two grand old men of Arcueil, Berthollet and Laplace, and the entire cult of French physics that surrounded them are entertainingly dissected through the period when French physics moved from uncompromising support of newtonianism to its near rejection with the wave theory of light. (Yes, there were fashions in science even then.) And, finally, Clément, Desormes and Carnot appear on the road to the second law of thermodynamics. Here, Fox endears himself to the working scientist who tires of the seemingly endless efforts by historians to dig up some obscure individual who 'did it first'. In his words, "I believe that, in Carnot's case, it is possible to place too much emphasis on the identification of traditions and precursors. As a result of recent research, we can now trace possible sources for most of the individual elements in his theory, but the originality of the way in which he synthesised these elements remains his unique achievement"

Fox writes for an audience far wider than the historian of science, and although these essays may present some challenge for the uninitiated, today's working scientist (looking beyond the arguments about supercolliders or the effects of retroviruses on the human population) could well profit from a dip into this book.

Jacqueline Reynolds is at Tarlswood, Back Lane, Easingwold, North Yorkshire YO6 3BG, UK. 